\begin{tabular}{|c|c|c|}
\hline PORT SAID ENGINEERING RESEARCH JOURNAL & Faculty of Engineering - Port Said University \\
( Production Engineering \& Mechanical Design) & No. 128-141
\end{tabular}

\title{
Mechanical Design and Simulation of Water Pipes Cleaning Robot
}

\author{
Mohammed Moustafa ${ }^{1}$, Sabreen A. Abdelwahab ${ }^{2}$ \\ Received: 22 November 2020; Accepted: 21 January 2021
}

\begin{abstract}
Pipelines have widely spread applications in the industry. Water, sewage, flammable liquid, high-pressure gasses, and oil are transported using pipelines. These pipelines are long, interconnected, and may be constructed underground or underwater. This makes their monitoring, periodic maintenance, and repair a hard job when done by human operators. Hence, a robot system capable of carrying out these complicated operations in pipelines is extremely requested. In this paper, a mechanical design and a prototype of an in-pipe robot system for cleaning $0.5 \mathrm{~m}$ inner diameter water pipes are presented. The proposed robot system is designed to perform cleaning operations for straight and curved horizontal water pipes based on the abrasion concept. The in-pipe robot system has three modules; forward and backward motion module, two identical cleaning modules that can move in rotational motion, and radial motion (in and out). These three modules are designed to have the robot's two main positions: an open position (for cleaning) and a closed position (while entering and getting out of the pipe). A 3D model has been built using SolidWorks software, then a finite element analysis was carried out on a robot's frame using two materials: Steel and Aluminum. However, the Steel material has been selected due to its high rigidity. The robot control system was done using Arduino software. Robot dynamics were simulated in a Simulink environment. The real-time robot testing showed that the proposed robot mechanism can complete the cleaning operations effectively. The developed robot is expected to minimize maintenance time, effort, and cost.
\end{abstract}

Keywords Water pipes, Cleaning robot, SolidWorks, Wheeled in-pipe robot, Arduino software, Finite element analysis, Simulink.

\section{INTRODUCTION}

Pipelines constitute an essential part of our lives today as they are the key means to supply several vital assets, such as water, gas, and oil. Also, pipelines are used in many applications such as chemical plants, power plants, and sewage systems. There are many factors affecting pipelines performance such as aging, corrosion, cracks, and also they are subjected to clog ups with debris and sediments after a long time of usage [1]- [3], and mechanical damage [3].

To keep pipelines functioning, several jobs are needed to be carried out regularly, these include maintenance and repairing [1]-[3], [4], inspection [3], [5], and cleaning [6], [7].

To reduce the cost and complications in inspecting and repairing robots are used [2], [3], [6], [8].

Robots are used in several applications since their existence such as heavy production industries, pipes visual inspection [9], gas pipelines [10], chemical pipelines, and water pipelines, etc. Also, underwater robots are used for inspection, maintenance, and cleaning [3], [11].


Egypt).Corresponding Author, email:mstafa.mohammed@yahoo.com

${ }^{2}$ Assistant professor in mechanical and mechatronics engineering, Production Technology Department, (Helwan University, Cairo, Egypt).

email: engsabreenabdallah@gmail.com

DOI: $\underline{10.21608 / \text { pserj.2021.43743.1064 }}$
The proper robot system should be light and rigid for optimum use of power [3], [6], and should be able to navigate all the topographies of the pipeline and beat any obstacles, its mechanical and electrical systems shouldn't be affected by the fluid existence, produce and store its power to afford long working times, should be as autonomous as possible, it should be supplied with tools needed to perform the required inspection and maintenance tasks, it should use systematic and efficient routines in moving inside the pipelines for inspection and execution of maintenance tasks, and it should give information report back to the maintenance station [2].

The cleaning robot consists of three main parts: the control system, the motion mechanism and the mechanism of cleaning or maintenance [12].

This paper is structured in ten sections, the first section is the introduction, and the second section is the literature review concerning the problem under consideration. The third section illustrates the proposed mechanism and working principle. The fourth section presents the system design and analysis in SolidWorks. Section five shows the kinematic model, and the locomotion strategy of the robot is given in section six. Control circuit and software are presented in section seven. Simulink model and dynamics simulation are shown in section eight. The section before the last presents the robot prototype and real-time testing, while the last section is the conclusions which are followed by the references used.

\section{LITERATURE REVIEW}

Working locations of in-pipe robots can be the inside of water pipes or sewer pipes. Here, it is a challenge to travel on uneven, wet, and slippery walls. Hence, these robots have a complex design as a combination of many locomotion approaches are 
used to travel in these working conditions. The mechanical parts need protection from fluid splashes or it might be fully water-proof as well [14].

The locomotion of the robot is to study how to develop a robot mechanism that allows effective movement. In-pipe robots can be categorized into many forms based on patterns of movement, as shown in Figure 1 [13]. These categories are wheels [15], [16], track/caterpillar [17], [18], inchworm [19], [20], walking [21], [22], screw [23], [24] and pig [25] types based on their motion mechanisms [14]. The most widely spread categories are wheeled, inchworm, snake and legged.

Current robots commonly move horizontally in pipelines successfully. However, complex pipeline configurations such as Y-shaped, or L-shaped pipelines (elbows) and/or T-shaped pipelines (branches) are hard to follow [13].
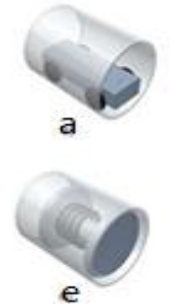

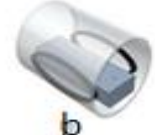

b

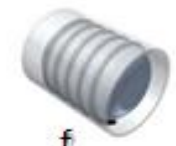



C

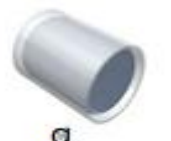

c

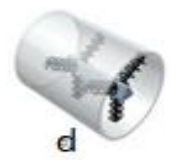

d

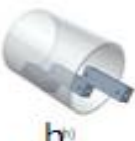

Figure 1: In-pipe robotic locomotion types: a) Wheel type. b) Track / caterpillar type. c) Leg type. d) Wall-press type. e) Inchworm type. f) Screw type. g) Pig type. h) Snake type, reproduced from [14]

In-pipe robots may be categorized based on the structures to 1) single-plane form or with arms $180^{\circ}$ apart [15], [16], 2) 3plane form or with arms separated $120^{\circ}$ [26], [27], 3) 4-plane form or with arms separated by $90^{\circ}$ [28] 4) 6-plane form or with arms separated by $60^{\circ}$ [29], as shown in Figure 2 [14].
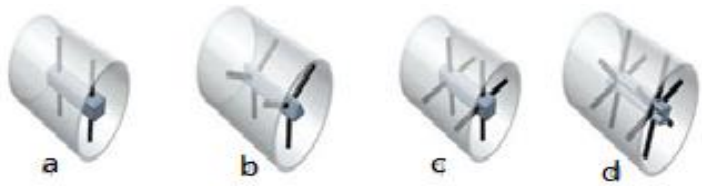

Figure 2: In-pipe robotic structure form: a) single-plane form. b) 3-plane form. c) 4-plane form. d) 6-plane form, reproduced from [14]

Wheeled robots have many advantages as simple design and control methodologies, the potential for miniaturization and energy efficiency [30]. They use their weight to keep contact between moving wheels and the wall of the pipe [31]-[33]. They can navigate pipelines with no upper pipe diameter limit. They can move through horizontal or slightly inclined pipelines. They might use magnetism [8], [34] which limits the working environment to those which are built mainly of ferrous materials, or they may work through pressing their wheels in contrast to the pipe surface using active means as linear actuators, passive means as springs or both of them [35]- [37]. Although being simple in mechanics, wheeled

robot's efficiency is not optimal for vertical surfaces.

The inchworm-type robots are comparatively simple to control and permit the robot to navigate the different features of the pipe inside, they use a vibration source as the primary driving force, together with a passive mechanical system to press against the wall of the pipe. They have very few parts, and easy to control, but they are unable to navigate junctions [38], [39]. Other inchworm robots have used an active way to press against the wall of the pipe. Although being more intricate than their passive alternatives, they are controlling their movements in a better manner and can easily switch direction [40]-[42]. Inchworm robots use a linear actuation for propulsion together with full control over the retraction and extension of their movements' limbs, which permit forward and backward movements inside the pipe. They can navigate straight and bend pipe sections. Inchworm robots move forward in steps rather than continuous movements as wheeled robots, hence they are slow. Conversely, they are more competent throughout climbing.

Snake and legged robots both have several degrees of freedom, which permit them a wide range of different motions. This leads to the use of more actuators, and the need for more compound control systems [43], [44]. They can navigate bends and junctions. Snake robots were used for pipe inspection [45][47]. These robots are composed of many modules attached to the use of actuated joints. Movement is primarily achieved through the use of traveling wave locomotion. They need high power actuators and have small payload capacity [41]. Sensors can't take a stable reading in snake robots because of their environment [48]. Generally, as pipelines have structured and uniform environments, the complexity of snake and legged robots may not be suitable in this application, particularly since robots with simpler motion techniques have proved their ability to navigate the various features in pipelines [2].

To add flexibility and robustness to the mechanisms hybrid locomotion systems exist to make the in-pipe robot capable of familiarizing and navigating in different pipe sizes and shapes. The wheeled wall-pressed robot type has a high-speed movement with a simple mechanical structure. The caterpillar wall-pressed robot type has a high ability in avoiding the problem of motion singularity though surpassing branches [49]. Whereas, wheeled wall pressing screw robot type has the finest navigation inside the curved pipe.

For the cleaning method; the most well-known cleaning methods used for in-pipe robots are mainly dependent on water pressure and impact abrasion [50]. Henceforth, in-pipe cleaning robots are grouped into two groups: 1) Tool-based [51], [52], and 2) Pressure-based [53], [54] cleaning robots, as shown in Figure 3.
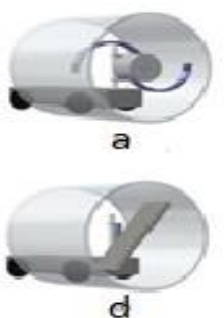



b

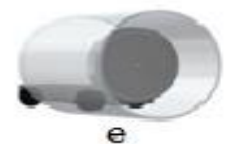

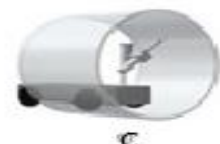

c

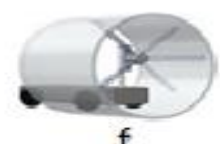

$f$
Figure 3: In-pipe robotic cleaning types: a) Impact abrasion with flails. b) Umbrella type. c) Commercial vehicle type. d) Cutter cleaner arm. e) Disk cleaner disk. f) Pressure-based [14]

\subsection{PROBLEM STATEMENT}

Fresh water pipe-lines are dominant, essential, valuable, unobserved, and regularly in a bad state. They transfer fresh 
water to buildings from the public water systems, these pipes are often manufactured of copper, ductile/cast iron, polyvinyl chloride, or polyethylene. Water pipes are subjected to damage because of excessive traffic, aging, earthquakes, and geological change, thus the pipe joints may not be wholly closed and outside materials (as polluted water and soil) may pollute the freshwater system. Generally, pipe replacement high cost made pipe cleaning and repairing the most preferred [13]. However, cleaning and maintaining pipelines are associated with several technical and operational problems when done with humans and therefore, in-pipe robots are an effective solution to overcome these issues with reasonable costs [1]-[8]. The above literature review shows that in-pipe robots are designed mostly for inspection or maintenance and less attention is given to cleaning robots despite their great importance in the water pipes cleaning field.

\section{THE PROPOSED MECHANISM AND THE WORKING PRINCIPAL}

A design and implementation of a new cleaning robot mechanical design are presented. The proposed system can move in straight or curved horizontal dry water pipes with 0.5 $\mathrm{m}$ diameter to suit the limited workspace and working conditions inside the water pipes. The required robot movements are forward and backward motion, and cleaning motion. Cleaning motion is based on the abrasion concept.

The cleaning robot mechanical design consists of three modules; forward and backward motion module, and two identical modules which are the front and rear cleaning modules. Figure 4 shows the design of the cleaning robot. The forward and backward motion module is mainly structured from a basic frame with four wheels. It is responsible for the robot's forward and backward motion, and it carries the control box. The other two cleaning modules are attached and fixed to it. And the front cleaning module contains four curved parts that move in a rotational motion, and they are responsible for the cleaning process. It has two motion types and two positions related to these curved parts (e.g. rotational and radial motions, closed or opened positions). To clean the inner surface of the water pipe a high friction material is used to cover the outer surface of the four curved parts to brush and clean the inner surface of the water pipe. The curved parts move radially out to have the open position of the robot and get ready for cleaning. After cleaning, the curved parts move radially in to have the closed position of the robot. In the robot's open position, these curved parts constitute together a part of cylinder shape (to take the pipe inner surface cylindrical shape). The closed position is required at the start while entering the water pipe and at the end while getting out of the water pipe. This module is used for rough cleaning. Three steeper motors were used to power the rotational motion

and forward and backward motion. Further, four stepper motors are used to have a radial motion for each cleaning module. The rear cleaning module is identical to the front cleaning module except that it is being used for finishing the cleaning process that has been started with the front cleaning module.

\section{MECHANISM MECHANICAL DESIGN AND ANALYSIS}

\subsection{Three-Dimensional Design of the Cleaning Robot}

SolidWorks software is used to build the $3 \mathrm{D}$ model and finite element analysis for the robot frame. In the beginning, the dimensions of each part were decided to have a suitable design and to attain dimension constraints. Then, each part was modeled individually. The cleaning robot was divided into three modules; the main frame which is responsible for forward and backward motion and the two cleaning modules.

All parts were combined to construct the final design in the next step. Where a bottom-up technique was used, in which the parts were built then integrated using mates. Mates generate geometric relationships, such as perpendicular, tangent, and coincident. The movements of the parts were restricted using these mates. Figure 4 shows the final design with all parts combined and the open and closed positions of the robot. Table 1 illustrates the parts description of the cleaning robot.



(a)

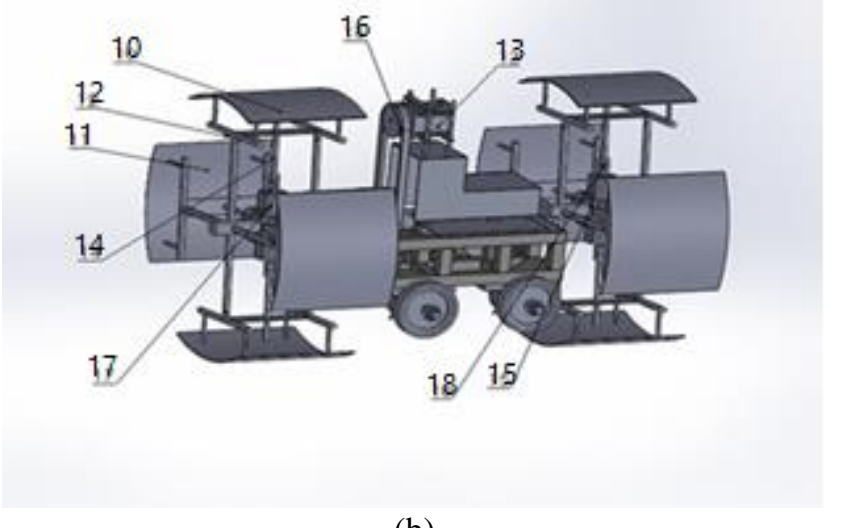

(b)

Figure 4: Cleaning robot design with all parts combined; (a) opened position, (b) closed position. 
Table 1: Parts description of the cleaning robot

\begin{tabular}{|c|c|c|}
\hline $\begin{array}{l}\text { Part } \\
\text { No. }\end{array}$ & Name & Qty \\
\hline 1 & Mainframe & 1 \\
\hline 2 & Main axis & 1 \\
\hline 3 & The rear axis of rotation & 1 \\
\hline 4 & The front axis of rotation & 1 \\
\hline 5 & Wheel & 4 \\
\hline 6 & Wheel lock nut & 4 \\
\hline 7 & $\begin{array}{l}\text { The motor of forwarding and backward } \\
\text { motion }\end{array}$ & 2 \\
\hline 8 & Motion drum & 4 \\
\hline 9 & Motion belt & 1 \\
\hline 10 & Curved parts used for rust cleaning & 10 \\
\hline 11 & Fixation bar 1 to fix the curved parts & 16 \\
\hline 12 & Fixation bar 2 to fix the curved parts & 16 \\
\hline 13 & $\begin{array}{l}\text { The motor of cleaning parts ( rotational } \\
\text { motion) }\end{array}$ & 1 \\
\hline 14 & The spindle of rotation of cleaning parts & 1 \\
\hline 15 & Base carrier of the motor of cleaning parts & 1 \\
\hline 16 & Motion belt & 1 \\
\hline 17 & $\begin{array}{l}\text { The motor of opening and closing } \\
\text { mechanism }\end{array}$ & 8 \\
\hline 18 & Coupling & 8 \\
\hline
\end{tabular}

\subsection{Working Area and Dimensions}

Following the robot design principles in section 4.1, a cleaning robot with $0.5 \mathrm{~m}$ maximum diameter and $1 \mathrm{~m}$ maximum length were developed to suit the inner dimensions of the water pipe. Figure 5 shows a simulation of the robot model moving inside the water pipe.

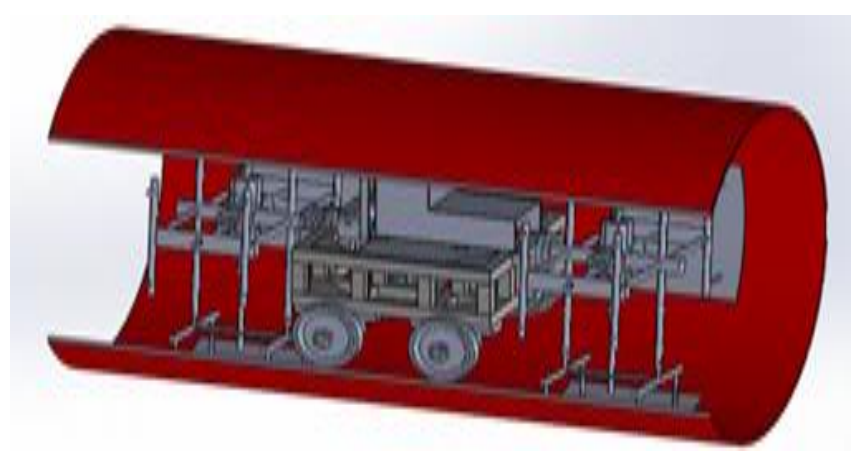

Figure 5: Robot moving inside the water pipe

\subsection{Finite Element Analysis}

Static analysis is performed on the frame of the cleaning robot to check its capability to stand under the loads being exposed to in water pipes, the deformation and the safety factor are tested for the selected material. Table 2 illustrated the selected materials for building up the frame. Both AIAS1035 Steel and Aluminum 1060 alloy are tested. The Steel frame has a mass of
$42 \mathrm{Kg}$, and the Aluminum frame mass is about a third of this value. An external force of 50 Newton was applied to the frame; the static test was performed for both Steel and Aluminum.

Table 2: Specification of used material for building robot frame [56][57]

\begin{tabular}{|c|c|c|}
\hline Material & $\begin{array}{c}\text { AIAS1035 } \\
\text { STEEL }(\mathbf{S S})\end{array}$ & $\begin{array}{c}\text { Aluminum } \\
\mathbf{1 0 6 0} \text { alloy }\end{array}$ \\
\hline Elastic Modulus $\left(\mathbf{N} / \mathbf{m}^{\mathbf{2}}\right)$ & $2.05 \mathrm{e}+11$ & $6.9 \mathrm{e}+10$ \\
\hline Density $\left(\mathbf{k g} / \mathbf{m}^{\mathbf{3}}\right)$ & 7850 & 2700 \\
\hline Yield strength $\left(\mathbf{N} / \mathbf{m}^{\mathbf{2}}\right)$ & 53000000 & 27574200 \\
\hline
\end{tabular}

\subsubsection{Static analysis for Steel frame}

The steel frame passed the static test well as shown in Figure 6. The maximum stress is fewer than the yield strength, so the part will not fail due to external load, as shown in Figure 6 (a) and (b). The maximum deformation is small, it is $5.926 \mathrm{~mm}$ as in Figure 6 (c). For the safety factor; it is clear that the robot frame is safe as the curve in Figure 6 (d) has a blue color.

\subsubsection{Static analysis of Aluminum frame}

The Aluminum frame passed the static test well as shown in Figure 7. The maximum stress is fewer than the yield strength, so the part will not fail due to external load, as shown in Figure 7 (a) and (b). The maximum deformation is $1.958 \mathrm{e}-01 \mathrm{~mm}$ which is much higher than the Steel frame case as in Figure 7 (c). For the safety factor, the frame passed the test as the curve is almost blue in Figure 7 (d), the value in the case of the Steel frame is much higher.

\subsubsection{Material selection}

The figures of finite element analysis show that the stress analysis of both materials is nearly the same. It is $3.513 \mathrm{e}+7$ $\mathrm{N} / \mathrm{m}^{2}$ and $1 \mathrm{e}+07 \mathrm{~N} / \mathrm{m}^{2}$ for steel and aluminum respectively, but with much higher yield stress in the case of Steel material. The Aluminum material showed more deformation than steel. Considering the factor of safety, it is clear that both materials pass the test, but Steel is selected because of its higher rigidity.

\section{KINEMATIC MODEL}

To get the robot position and orientation the kinematic model should be developed. Considering a four-wheeled mobile robot with standard wheels with radius $r_{n}$; the wheel is apart from the origin of the robot frame $P$ by a distance $l_{n}, \alpha_{n}$ is the angle of rotation of the wheel measured from the $\mathrm{x}$-axis of the robot frame, $\beta_{n}$ is the steering angle of the wheel measured from the axis perpendicular to the wheel plane, $\emptyset_{n}$ is the wheel rotation angle, where $n$ is the wheel number $(n=1: 4)$ and $\theta$ is the angle between the inertial $\mathrm{x}$-axis (world coordinates) and $x r$-axis, as shown in Figure 8 (a) and (b). 


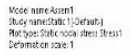



(a)
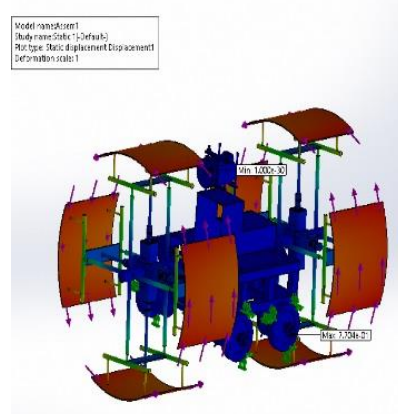

(c)

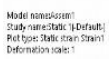

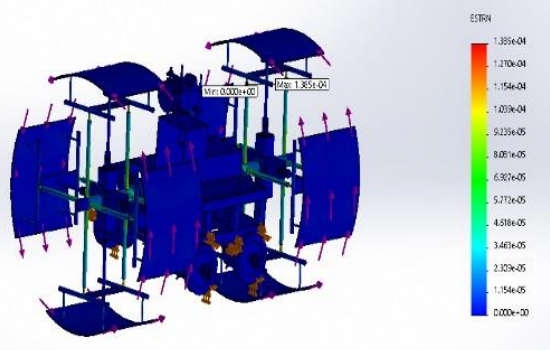

(b)

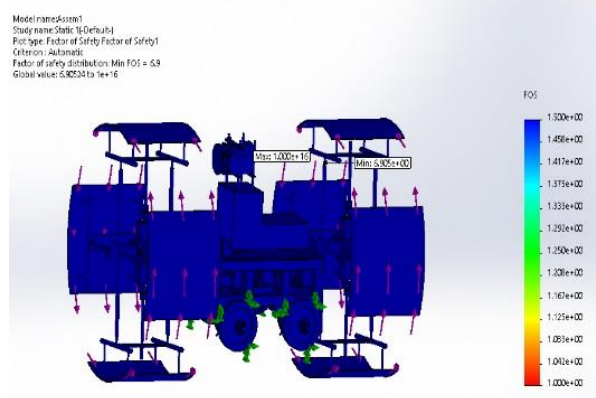

(d)

Figure 6: Static analysis of Steel frame; (a) stress, (b) strain, (c) displacement, and (d) factor of safety.
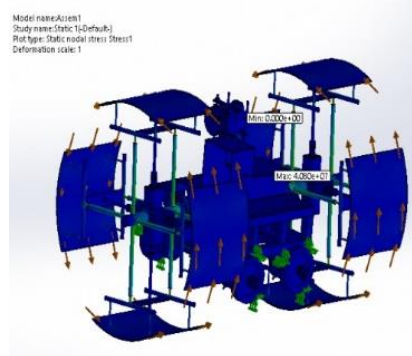

(a)



(c)




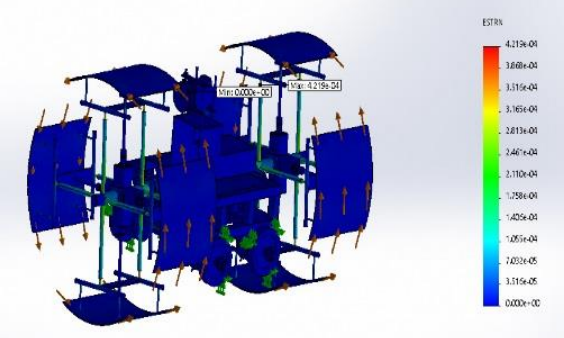

(b)

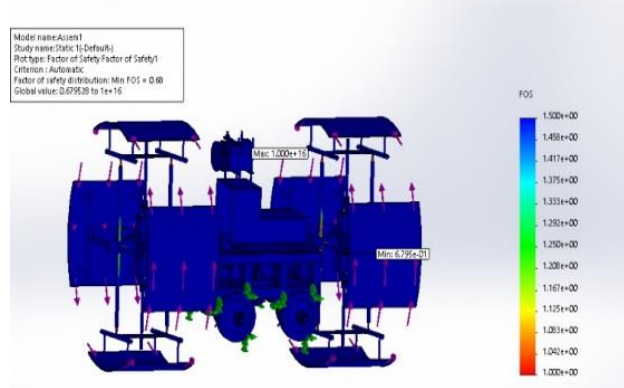

(d)

Figure 7: Static analysis of Aluminum frame; (a) stress, (b) strain, (c) displacement, and (d) factor of safety 
Assume that the robot frame is rigid with non-deformable wheels, wheel-wall are in contact at a single point A, the pipe is horizontal, and the two front wheels of the robot are independently driven. Hence, constraints are as in the following, as shown in Figure 8 (c):

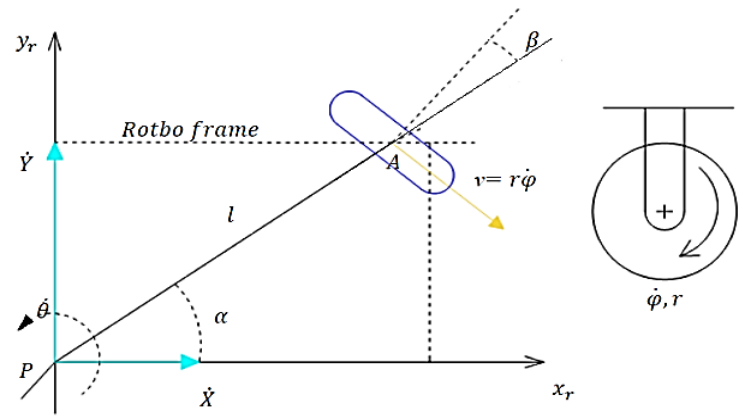

(a)



(b)



(c)

Figure 8: Robot kinematics (a) and (b) Robot dimension parameters (c) Analysis of motion constraints vectors.

The rolling constraint of one wheel:

$[\sin (\alpha+\beta)-\cos (\alpha+\beta) \quad-l \cos (\beta)] \dot{\varepsilon}_{R}-r \dot{\varnothing}=0$

No- sliding constraint of one wheel:

$[\cos (\alpha+\beta) \sin (\alpha+\beta) \quad l \sin (\beta)] \dot{\varepsilon}_{R}=0$

Where $\dot{\varepsilon}_{R}=\left[\begin{array}{c}\dot{X}_{r} \\ \dot{Y}_{r} \\ \dot{\theta}\end{array}\right]$

$\dot{\varepsilon}_{R}$ is the global velocity, $\dot{X}_{r}$ is the velocity component in the $x r$ axis, $\dot{Y}_{r}$ is the velocity component in the $y_{r}$-axis, and $\dot{\theta}$ is the angular velocity of the robot frame for word coordinates $\left(\mathrm{X}_{l}\right.$, $\mathrm{Y}_{l}$ ).

Combining the rolling constraints for the four standard wheels: $\left[\begin{array}{ccc}\sin \left(\alpha_{1}+\beta_{1}\right) & -\cos \left(\alpha_{1}+\beta_{1}\right) & -l_{1} \cos \left(\beta_{1}\right) \\ \sin \left(\alpha_{2}+\beta_{2}\right) & -\cos \left(\alpha_{2}+\beta_{2}\right) & -l_{2} \cos \left(\beta_{2}\right) \\ \sin \left(\alpha_{3}+\beta_{3}\right) & -\cos \left(\alpha_{3}+\beta_{3}\right) & -l_{3} \cos \left(\beta_{3}\right) \\ \sin \left(\alpha_{4}+\beta_{4}\right) & -\cos \left(\alpha_{4}+\beta_{4}\right) & -l_{3} \cos \left(\beta_{4}\right)\end{array}\right]\left[\begin{array}{c}\dot{X}_{r} \\ \dot{Y}_{r} \\ \dot{\theta}\end{array}\right]-$

$\left[\begin{array}{cccc}r_{1} & 0 & 0 & 0 \\ 0 & r_{2} & 0 & 0 \\ 0 & 0 & r_{3} & 0 \\ 0 & 0 & 0 & r_{4}\end{array}\right]\left[\begin{array}{l}\dot{\phi}_{1} \\ \dot{\emptyset}_{2} \\ \dot{\emptyset}_{3} \\ \dot{\emptyset}_{4}\end{array}\right]=0$

Introducing notation equation (4) can be written as

$C_{p} \dot{\varepsilon}_{R}-W \dot{\varnothing}=0$

Combining the no-sliding constraints for the four standard wheels:

$\left[\begin{array}{ccc}\cos \left(\alpha_{1}+\beta_{1}\right) & \sin \left(\alpha_{1}+\beta_{1}\right) & l_{1} \sin \left(\beta_{1}\right) \\ \cos \left(\alpha_{2}+\beta_{2}\right) & \sin \left(\alpha_{2}+\beta_{2}\right) & l_{2} \sin \left(\beta_{2}\right) \\ \cos \left(\alpha_{3}+\beta_{3}\right) & \sin \left(\alpha_{3}+\beta_{3}\right) & l_{3} \sin \left(\beta_{3}\right) \\ \cos \left(\alpha_{4}+\beta_{4}\right) & \sin \left(\alpha_{4}+\beta_{4}\right) & l_{3} \sin \left(\beta_{4}\right)\end{array}\right]\left[\begin{array}{c}\dot{X}_{r} \\ \dot{Y}_{r} \\ \dot{\theta}\end{array}\right]=0$

Introducing notation equation (6) can be written as

$C_{N} \dot{\varepsilon}_{R}=0$

To express velocities in the world coordinate system $\left(\mathrm{X}_{l}, \mathrm{Y}_{l}\right)$

$\dot{\varepsilon}_{R}=R \dot{\varepsilon}_{l}$

$R=\left[\begin{array}{ccc}\cos \theta & \sin \theta & 0 \\ -\sin \theta & \cos \theta & 0 \\ 0 & 0 & 1\end{array}\right]$

$\dot{\varepsilon}_{l}=R^{-1} \dot{\varepsilon}_{R}$

Robot motion via combining rolling and no-sliding constrains to yield:

$\left[\begin{array}{l}C p \\ C_{N}\end{array}\right] R \dot{\varepsilon}_{l}=\left[\begin{array}{c}W \dot{\varnothing} \\ 0\end{array}\right]$

In forward kinematics: given the wheel speed; the global velocity will be found as:

$\dot{\varepsilon}_{l}=R^{-1}\left[\begin{array}{l}C p \\ C_{N}\end{array}\right]^{-1}\left[\begin{array}{c}W \dot{\varnothing} \\ 0\end{array}\right]$

Inverse kinematics: given global velocity find wheel speed

$\dot{\emptyset}=W^{-1} C p R \dot{\varepsilon}_{l}$

The robot frame width and length are equal to $300 \mathrm{~mm}, l=212$ $\mathrm{mm}, r=100 \mathrm{~mm}$.

For the cleaning mechanism of the robot shown in Figure 9; the total cleaning force required $\mathrm{Fc}$ is based on the coefficient of friction between the cleaning parts and the pipe inside wall $\mu$, and the tangential force $\mathrm{f}$.

$\mathrm{Fc}=\mu \mathrm{f}$

and

$\mathrm{f}=t / a$

Where $\tau$ is the motor torque, and $a$ is the length of moment arm which equals to the pipe radius. 


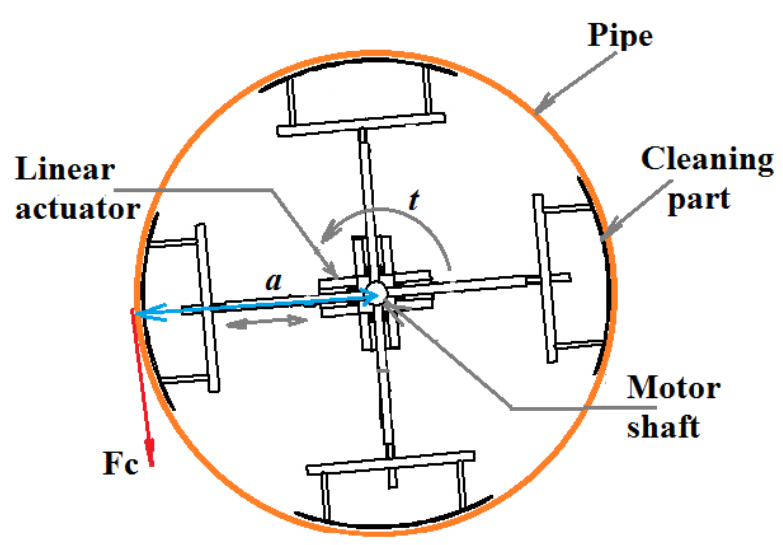

Figure 9: Cleaning motion mechanism

\section{LOCOMOTION APPROACH}

Locomotion inside the pipe is based on the robot's four wheels. For rotation; the velocities of the two front wheels are changed so that the robot turns towards the slower wheel. For autonomous navigation to different features inside the pipe; the robot must realize its position and orientation relative to the inside wall of the pipe, and it must have the ability to turn himself to track the trajectory of the inside wall. The planned locomotion procedure utilizes six Infra-Red (IR) sensors located around the robot mechanism, four sensors are positioned at the left and right sides of the robot, and two sensors are positioned at the front and back of the robot, as shown in Figure 10. These sensors will be used to measure the distances between the robot and the obstacles or bodies placed around it. The readings taken from the IR sensors will be used to detect a wall section (obstacle) on the pipe wall. Then, two vectors will be computed; a tangent vector and a perpendicular vector to the wall. These two vectors are combined, and the robot is steered in the direction of the new vector keeping a certain distance between the wall and the robot to be sure that the robot neither steers a way of or into the wall while following the wall trajectory; this is called "Follow wall behavior" [58]. The procedure is mentioned in the following:

1. To follow the wall on the left side, the two left sensors with the shortest distance measured are used. Hence, two points are denoted on the wall $P_{1}$ and $P_{2}$, which can be used to build the tangent vector Ut.

$$
\mathrm{Ut}=\left[P_{2}-P_{1}\right]
$$

2. The tangent vector is normalized.

$$
\mathrm{U}^{\prime} \mathrm{t}=\frac{\mathrm{Ut}}{\|\mathrm{Ut}\|}
$$

3. Using point $P_{l}$ on the vector tangent to the wall, and the vector U't a new vector can be computed from point $P$ and perpendicular (pointed) to the wall and close to $P_{l}, P$ is the origin of the robot.

$$
\mathrm{Up}=\left(P_{l}-P\right)-\left(\left(P_{l}-P\right) . \mathrm{U} ' \mathrm{t}\right) \mathrm{U} \text { 't }
$$

4. A vector that points in the opposite direction of $\mathrm{Up}$ is computed Uo, and weighted by the distance needed to be maintained from the wall $d$.

$$
\mathrm{Uo}=-d \frac{\mathrm{Up}}{\|\mathrm{Up}\|}
$$

5. Combining these two vectors Up and Uo the resultant vector will point away from the wall if the robot is closer to the wall than $d$, and points to the wall if the robot is away with a distance greater than $d$.

$$
\mathrm{U} ' \mathrm{p}=\mathrm{Up}-d \frac{\mathrm{Up}}{\|\mathrm{Up}\|}
$$

6. The two vectors are summed into a single vector Uf that points to the new direction to follow the wall.

$$
\mathrm{Uf}=c \mathrm{U}^{\prime} \mathrm{t}+b \mathrm{U} \text { 'p }
$$

Where $c$ and $b$ are arbitrary parameters.



Figure 10: Robot with sensors in the pipe.

\section{CONTROL CIRCUIT AND SOFTWARE}

Control system design started with the building of the control circuit hardware, then the software development took place by producing a flowchart of the required tasks by the robot followed by full code illustration using Arduino software. Figure 11 shows a schematic diagram of the control circuit, Figure 12 presents a real photo of the control circuit. Figure 13 shows a flowchart for tasks required by the robot, and Table 3 illustrates the control circuit specifications.



Figure 11: Schematic diagram of the robot control circuit. 


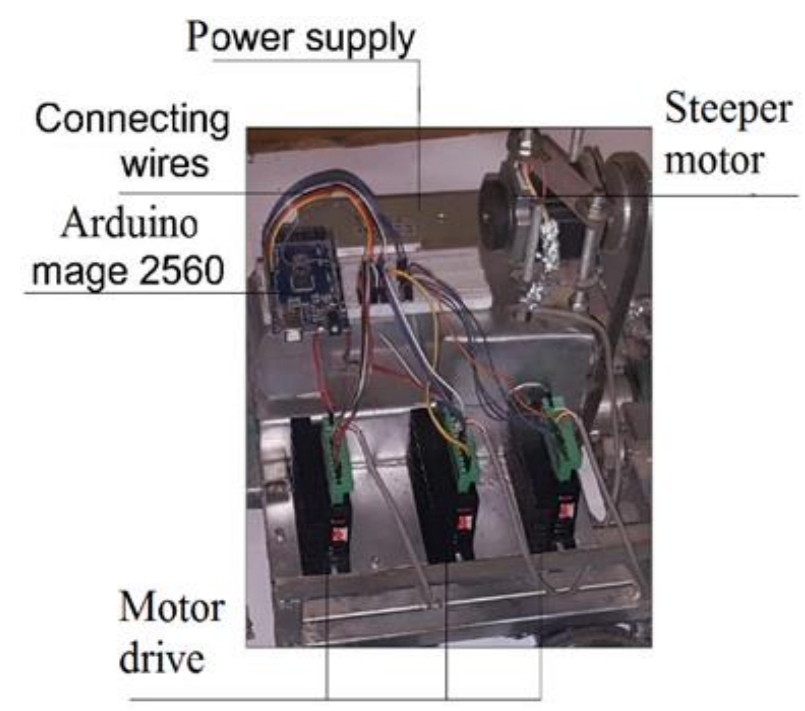

Figure 12: Real photo of the control circuit.

Table 3: Control circuit specifications

\begin{tabular}{|c|c|c|c|c|}
\hline No. & Part & $\begin{array}{l}\text { No. } \\
\text { of }\end{array}$ & Specifications & Function \\
\hline 1 & $\begin{array}{c}\text { Motor } \\
\text { Nema } 23\end{array}$ & 3 & $\begin{array}{l}\text { Torque: } 16 \mathrm{~kg} . \mathrm{cm} \\
\text { Current: } 2.9 \mathrm{~A} \\
\text { step angel: } 1.8 \\
\text { Motor speed: } 800 \\
\text { r.p.m }\end{array}$ & $\begin{array}{l}\text {-Robot forward } \\
\text { and backward } \\
\text { motion, } \\
\text {-Robot cleaning } \\
\text { motion }\end{array}$ \\
\hline 2 & $\begin{array}{c}\text { Motor } \\
\text { Nema } 17\end{array}$ & 8 & $\begin{array}{c}\text { Torque: } 3 \mathrm{~kg} . \mathrm{cm} \\
\text { Current: } 0.8 \mathrm{~A} \& \\
0.9 \mathrm{~A} \\
\text { Step angel: } 1.8\end{array}$ & $\begin{array}{c}\text { Switching } \\
\text { between opened } \\
\text { and closed } \\
\text { positions. }\end{array}$ \\
\hline 3 & $\begin{array}{l}\text { Arduino } \\
\text { Mega } 2560 \\
\text { board }\end{array}$ & 1 & $\begin{array}{l}\text { A microcontroller } \\
\text { board based on the } \\
\text { ATmega } 2560 \text {, } \\
\text { with } 54 \text { digital } \\
\text { input/output pins } \\
\text { (of which } 15 \text { can be } \\
\text { used as PWM } \\
\text { outputs), } 16 \text { analog } \\
\text { inputs, } 4 \text { UARTs } \\
\text { (hardware serial } \\
\text { ports), a } 16 \mathrm{MHz} \\
\text { crystal oscillator. }\end{array}$ & $\begin{array}{l}\text { Control program } \\
\text { development. }\end{array}$ \\
\hline 4 & Drive 6600 & 4 & $\begin{array}{l}\text { TB6600 single- } \\
\text { axis 4A stepper } \\
\text { motor driver } \\
\text { controller 9-40V } \\
\text { micro-step CNC } \\
\text { power control } \\
\text { sockets }\end{array}$ & $\begin{array}{l}\text { Contact the } \\
\text { motor to the } \\
\text { control circuit }\end{array}$ \\
\hline 5 & $\begin{array}{l}\text { Power } \\
\text { supply }\end{array}$ & 1 & $12 \mathrm{DC}$ volt, $30 \mathrm{~mA}$ & DC power source \\
\hline 6 & $\begin{array}{l}\text { USB } 2.0 \\
\text { cable }\end{array}$ & 1 & $\begin{array}{l}\text { Data transfer } \\
\text { speed is } 480\end{array}$ & $\begin{array}{c}\text { Connect the } \\
\text { Arduino } \\
\text { board to PC. }\end{array}$ \\
\hline 7 & Adaptor & 1 & $\begin{array}{c}\text { Input } 100-240 \mathrm{~V} \\
50 / 60 \mathrm{~Hz}, 0.2 \mathrm{~A} \\
\text { Output } 5 \mathrm{~V}\end{array}$ & $\begin{array}{l}\text { Connect the } \\
\text { Arduino board to } \\
\text { the power source }\end{array}$ \\
\hline
\end{tabular}



Figure 13: Flowchart for cleaning operation 


\section{SIMULINK MODEL AND DYNAMICS SIMULATION}

After designing the robot model on SolidWorks, the 3D design was moved to the Simulink environment as Simulink blocks to simulate robot motion and dynamics. Figure 14 illustrates the created robot Simulink model.

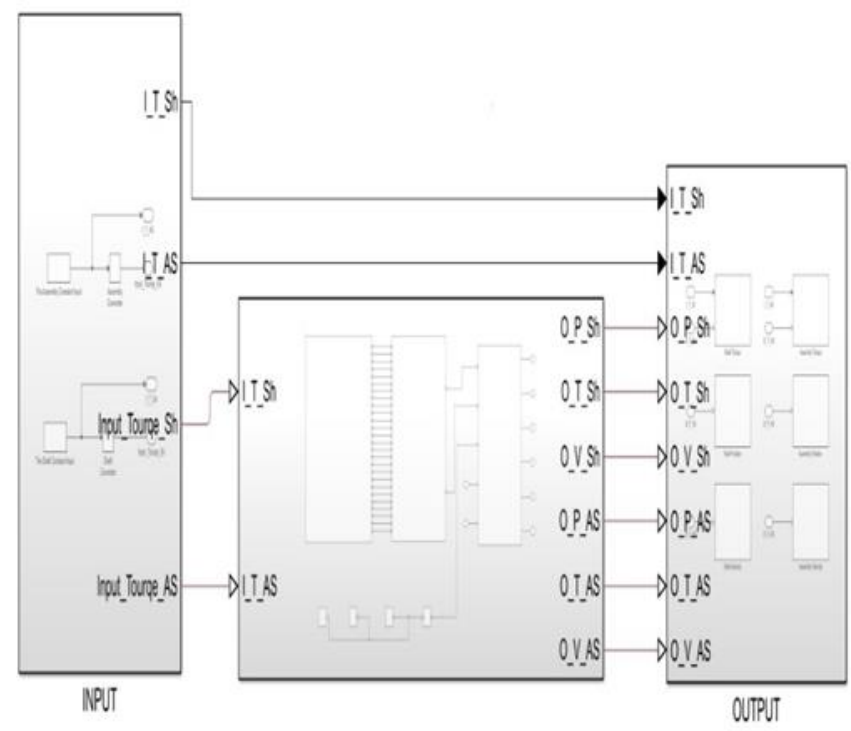

Figure 14: Simulink blocks

\subsection{Open-Loop Dynamics}

\section{a. Forward motion}

The driving motor was supplied by $300 \mathrm{mN}^{*} \mathrm{~m}$ input torque, then the position and velocity of the robot were measured. Figures 15 and 16 show the input position and the speed of the robot forward motion inside the pipe (in the $\mathrm{x}$-direction).

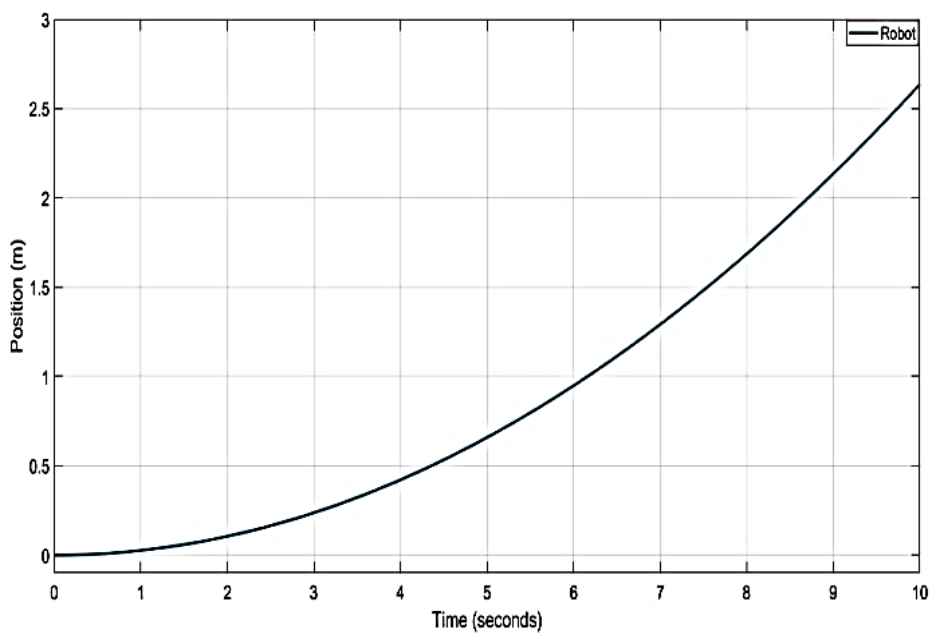

Figure 15: Robot position (in $x$-direction)

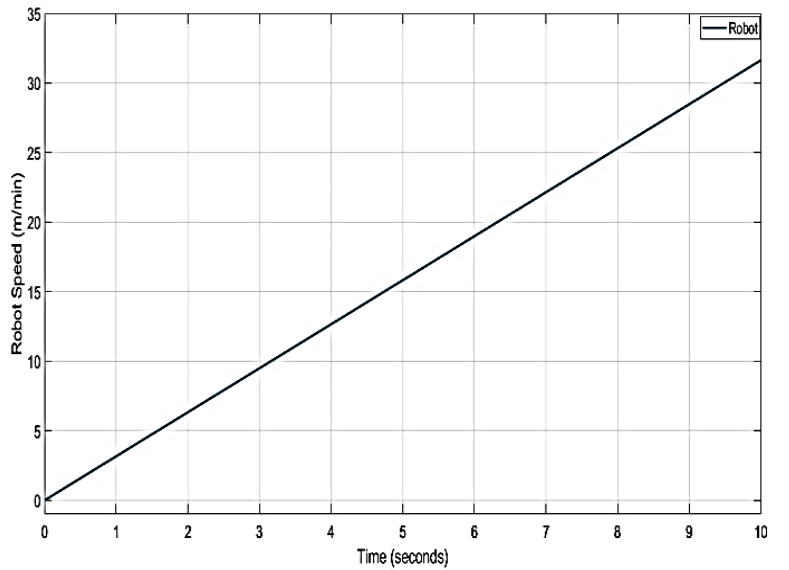

Figure 16: Robot forward motion velocity

\section{b. Cleaning motion}

The driving motor was supplied by $300 \mathrm{mN} * \mathrm{~m}$ input torque, then position and velocity of the robots' curved parts motion were measured. Figures 17 and 18 show the input position and speed of robots' curved parts rotational motion inside the pipe.



Figure 17: Robots' curved parts position

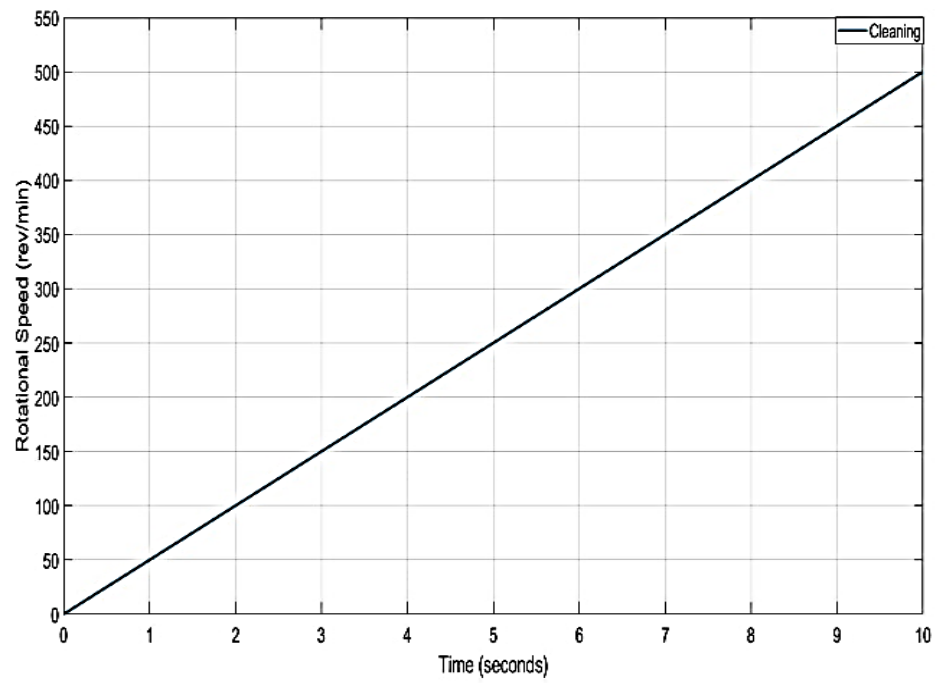

Figure 18: Robots' curved parts motion velocity 


\subsection{Closed-Loop Dynamics Simulation with PID Controller}

A resistance of $100 \mathrm{~N} . \mathrm{m}$ was applied against the robot motion to resemble the water resistance inside the pipe. A PID controller is added to the Simulink model to check the closed-loop dynamics of the system, as shown in Figure 19. The step response and the controller parameters are shown in Figure 20. Figure 21 shows the input-output signal (front wheels' number of revolutions per minute), robot speed signal and torque signal in forward motion, and Figure 22 shows the input-output signal and torque signal in rotational or cleaning motion.
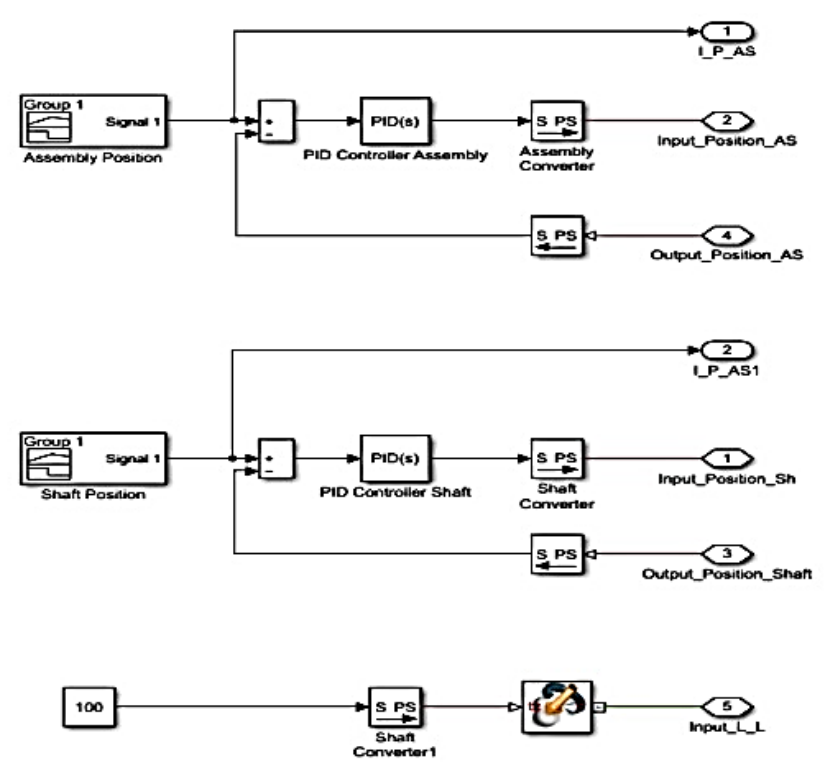

Figure 19: Simulink model with PID controller

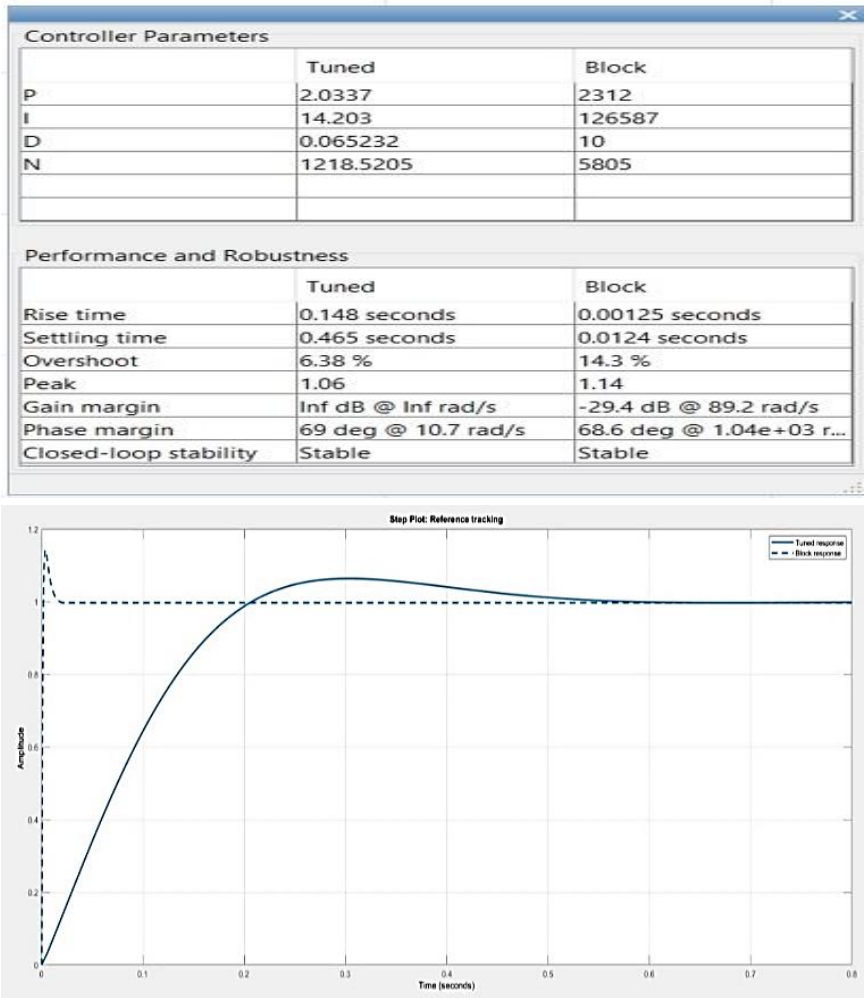

(a)

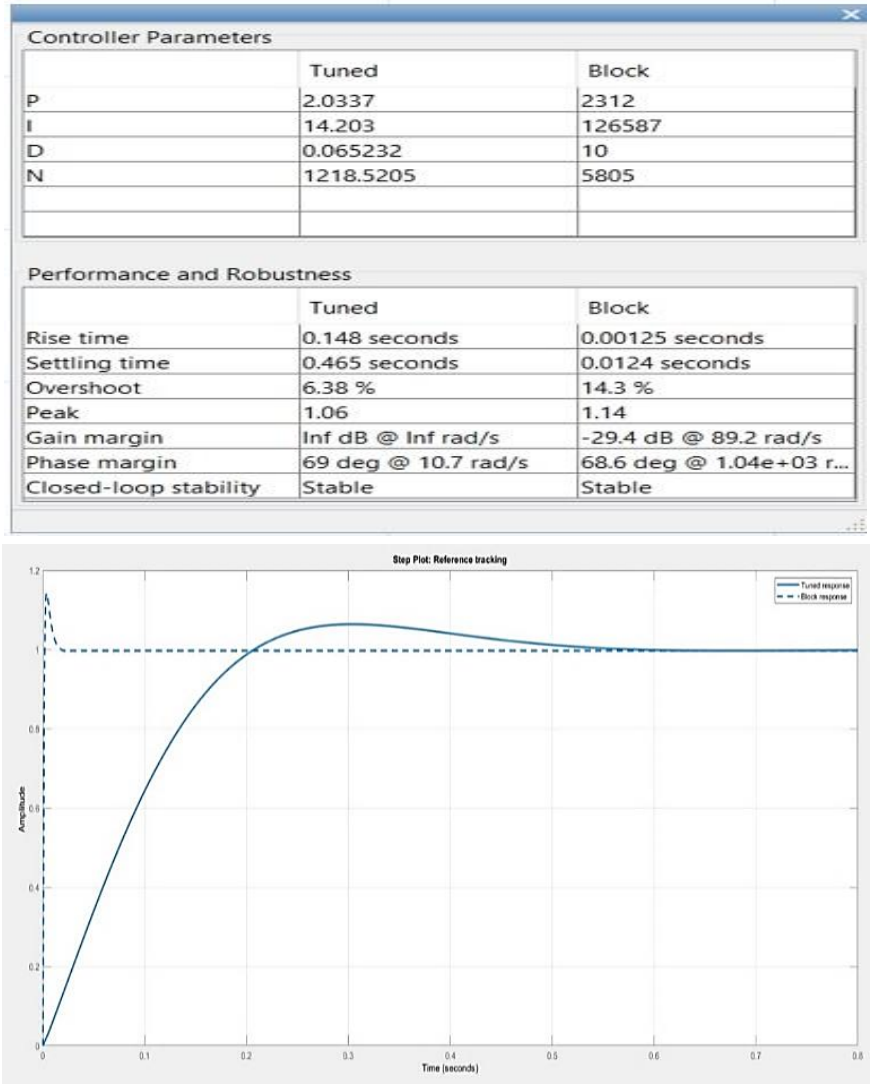

(b)

Figure 20: Parameters of the PID controller and System step response (a) Forward motion, (b) Rotational motion. 


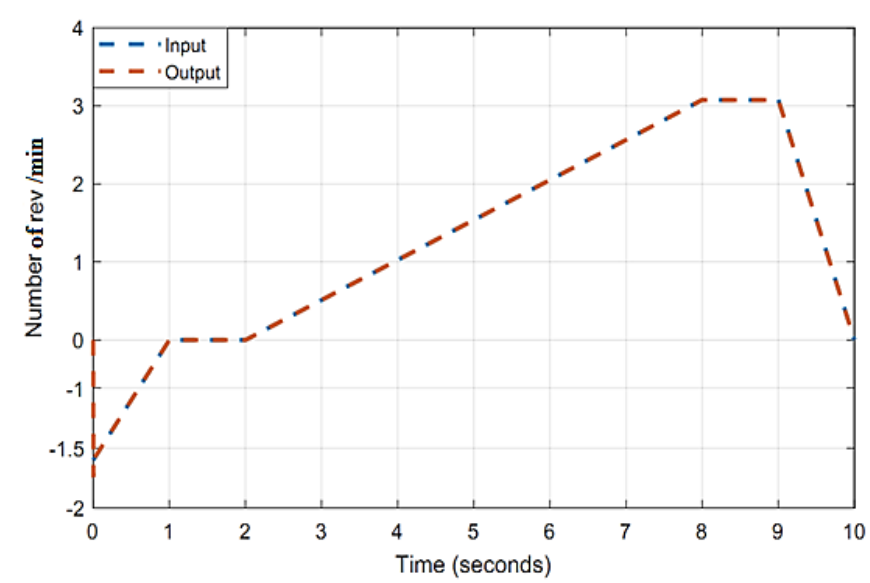

(a)

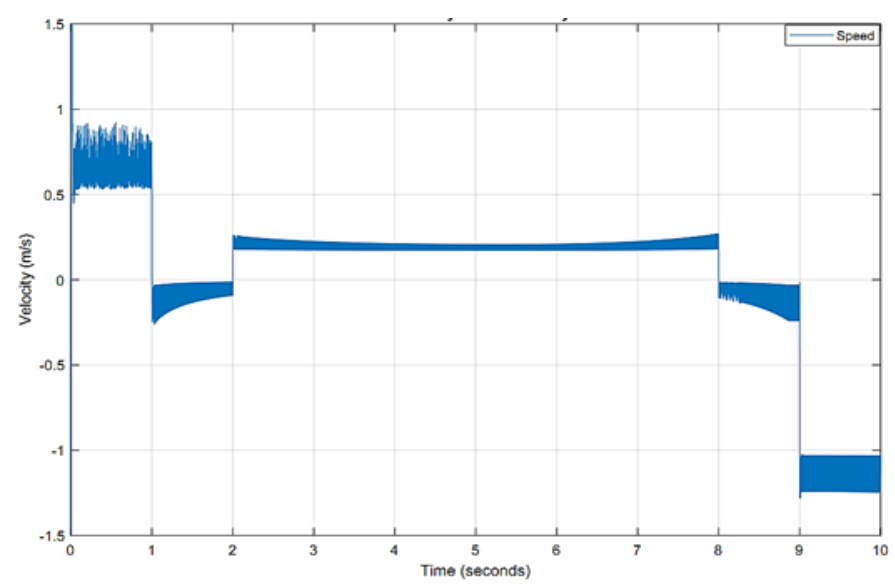

(b)

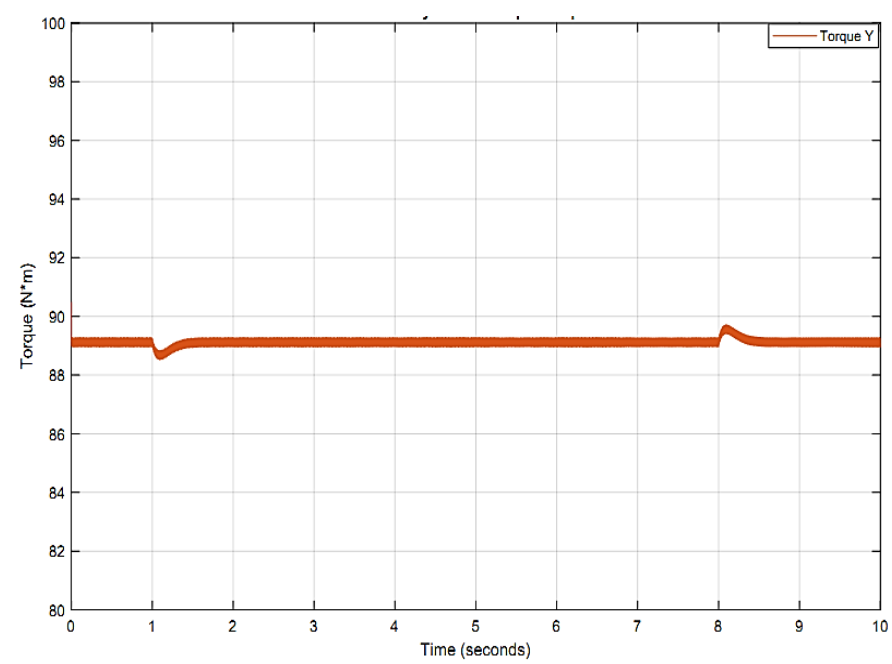

(c)

Figure 21: (a) Input-output signal in forward motion, (b) Robot speed signal, (c) Torque signal.

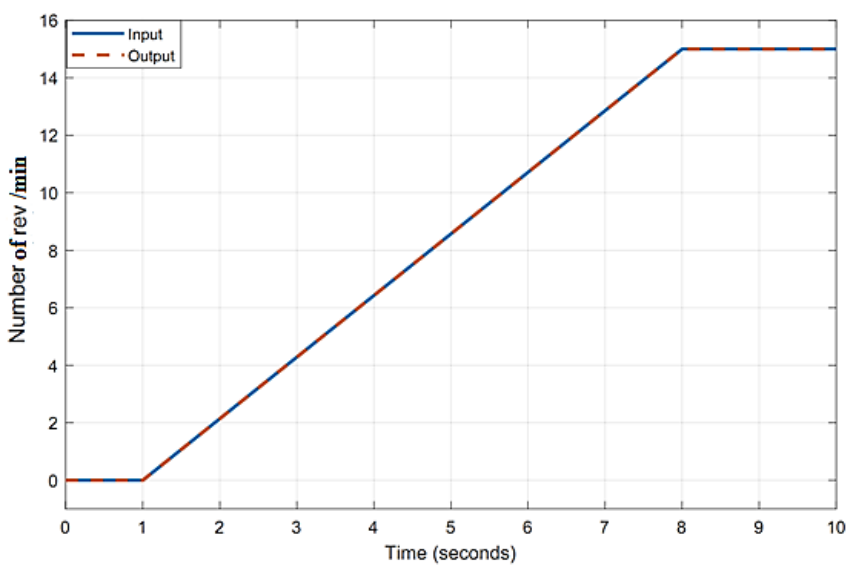

(a)

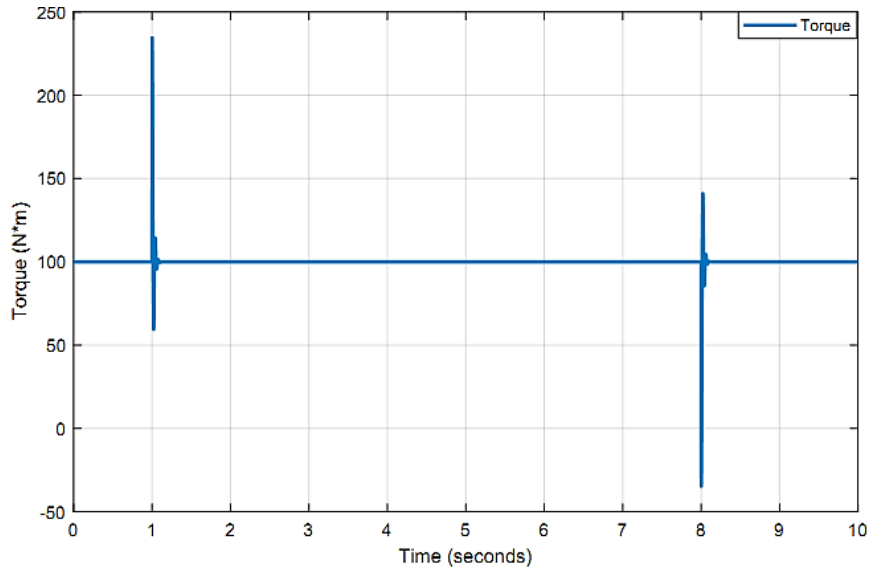

(b)

Figure 22: (a) Input-output signal in rotational motion, (b) Torque signal.

\section{ROBOT PROTOTYPE AND REAL-TIME TESTING}

After the design and modeling stages of the proposed robot mechanism, a robot prototype was fabricated with a weight of $43 \mathrm{~kg}$ from Steel. Figure 23 shows the image of the robot after the completion of the prototype manufacturing. Figure 24 shows a photo of the robot inside the test pipe.



Figure 23: Robot prototype final form

A real test pipe was manufactured to simulate the water pipe under consideration with $2 \mathrm{~m}$ length, the robot motor related to the forward and backward motion was connected to the load, then-current, voltage and rpm were measured using a 
multimeter and tachometer. Hence, the torque can be calculated at each rpm assuming motor efficiency of $70 \%$ using equation (22) [59].

$\tau=\mathrm{I} * \mathrm{~V} * \mathrm{E} / \omega=(\mathrm{I} * \mathrm{~V} * \mathrm{E} * 60) /(\mathrm{rpm} * 2 \pi)$

where

I: current, measured in amperes (A);

$\mathrm{V}$ : applied voltage, measured in volts $(\mathrm{V})$.

$\tau$ : torque, measured in Newton-meters (N.m);

$\omega$ : angular speed, measured in radians per second ( $\mathrm{rad} / \mathrm{s})$.

rpm: rotational speed in revolutions per minute.

E: Efficiency of the motor

Linear velocity was calculated also knowing rpm, $\omega$, and wheel radius using equation (23).

$v=\mathrm{r} \omega$

Distance moved by the robot was measured against time as well. Figure 25 shows the distance-time relation, while Figure 26 shows the torque-linear speed relation. Where the linear speed of the robot decreased as the toque increased.

Further, by calculating the $\tau$ related to the motor responsible for cleaning and knowing the moment arm, hence the cleaning force can be calculated.

Figure 27 shows the relation of torque- cleaning force relation. Where the cleaning force increases as the torque increases.

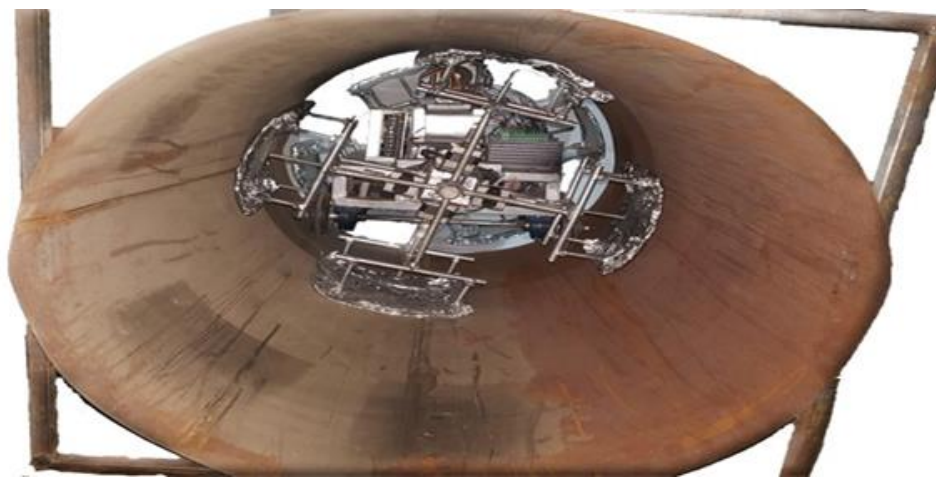

Figure 24: Robot inside the test pipe.

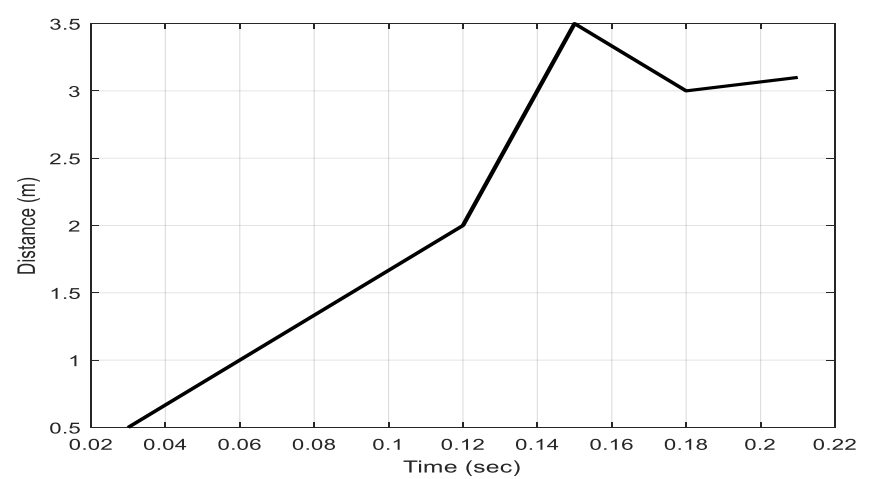

Figure 25: Time-distance relation.

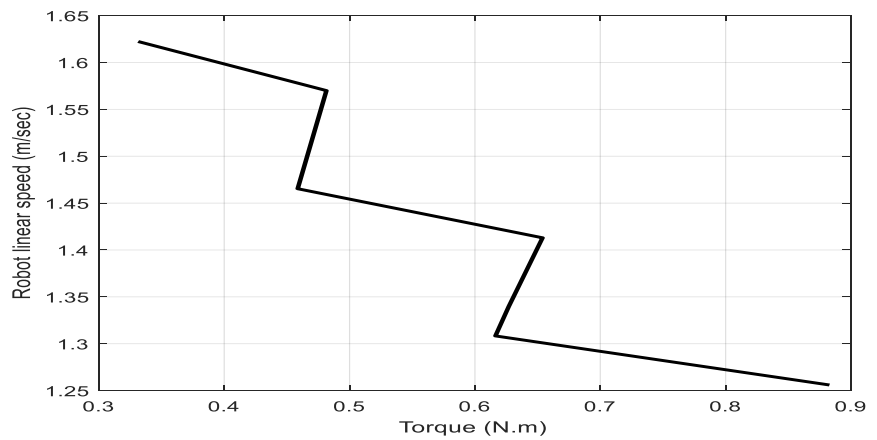

Figure 26: Torque-linear speed relation.



Figure 27: Torque-cleaning force relation.

\section{0 .CONCLUSIONS}

A new cleaning robot mechanical design has been developed, fabricated and tested. The robot can move in straight or curved horizontal water pipes. It has one driving module and two identical cleaning modules. The maximum length is $1 \mathrm{~m}$, the maximum diameter is $0.5 \mathrm{~m}$, and the maximum weight is $43 \mathrm{Kg}$. The robot offers many advantages as good cleaning ability, good automation, a wide range of application and low cost. Indoor water quality will be improved, and living and health standards will be increased.

The robot was tested in SolidWorks, finite element analysis has been done using Steel and Aluminum to check the frame of the robot against working loads, both materials passed the test, but Steel has been selected because of its high rigidity. Robot dynamics were simulated in a Simulink environment. A real test was performed in a test pipe. Relations of torque-speed, and torque-cleaning force, time-moved distance are plotted and showed that as the torque increases the speed decreases while the cleaning force increases.

In the future; the development of a robot mechanism that can navigate in an inclined or vertical pipes, and can work in active water pipes should be investigated. Also, a camera could be attached for inspection issues.

\section{Credit Authorship Contribution Statement:}

Mohammed Moustafa: conceptualization, formal analysis, investigation, resources, original draft.

Sabreen A Abdelwahab: methodology, validation, supervision, formal analysis, writing, review and editing.

\section{Declaration of Competing Interest}

The authors declare that they have no known competing financial interests or personal relationships that could have appeared to influence the work reported in this paper. 


\section{References}

[1] A. S. Z. Abidin, M. F. A. M. Pauzi, M. M. Sadini, M. H. Zaini, S. C. Chie, S. Mohammadan, and M. S. Jamaluddin, Development of track wheel for in-pipe robot application. Procedia Computer Science, 2015, 76: 500.

[2] A. Bekhilt, A. Dehghani, R. Richardson, Kinematic analysis and locomotion strategy of a pipe inspection robot concept for operation inactive pipelines. International Journal of Mechanical Engineering and Mechatronics, 2012, 1.2: 15-27.

[3] R. R. DhumalL, H. H. Patil, A. R. Dabhade, H. M. Papal, and N. K. Kulkarni, "A review of pipe inspecting robot and its application,” Int. J. Recent Innov. Eng. Res., pp. 90-94, 2017. [4] L. A. Rybalkin, Development of a robotic system of nonstripping pipeline repair by reinforced polymeric compositions. E\&ES, 2018, 134.1: 012052.

[5] S. Hajjaj, I. Khalid, Design, and development of an inspection robot for oil and gas applications. International Journal of Engineering \& Technology, 2018, 7.435: 5.

[6] A. S. Z. Abidin, M. F. A. M. Pauzi, M. M. Sadini, M. H. Zaini, S. C. Chie, S. Mohammadan \& C. Y. Ming, Development of cleaning device for in-pipe robot application. Procedia Computer Science, 2015, 76: 506-511.

[7] P. Dhananchezhiyan, S.S.Hiremath, M.Singaperumal, and R. Ramakrishnan, Design and development of a reconfigurable type autonomous sewage cleaning mobile manipulator. Procedia Engineering, 2013, 64: 1464-1473.

[8] F.Tâche, W. Fischer, R. Moser, F. Mondada, \& R. Siegwart, Adapted magnetic wheel unit for compact robots inspecting complex shaped pipe structures. In: 2007 IEEE/ASME international conference on advanced intelligent mechatronics. IEEE, 2007. p. 1-6.

[9] AL. Hajry, S. S. Hanaa, G. R. Rameshkumar, Design and Testing of Pipeline Inspection Robot. International Journal of Engineering Innovations and Research, 2013, 2.4: 319.

[10] K. P. Liu, B. L. Luk, Y. T. Chan, Service robot for inspecting exterior gas pipes of high rise buildings. In: Proceedings of the World Congress on Engineering. 2009.

[11] R. Bradbeer, S. Harrold, F. Nickols, \& L. F. Yeung, An underwater robot for pipe inspection. In: Proceedings Fourth Annual Conference on Mechatronics and Machine Vision in Practice. IEEE, 1997. p. 152-156.

[12] M. Urdaneta, C. Garcia, G. Poletti, G. Ejarque, R. Saltaren, and R. Aracil, Development of a novel autonomous robot for navigation and inspect in oil wells. Journal of Control Engineering and Applied Informatics, 2012, 14.3: 9-14.

[13] L. A. Mateos, M.Vincze, Dewalop-monolithic multimodule in-pipe robot system. In: International Conference on Intelligent Robotics and Applications. Springer, Berlin, Heidelberg, 2011. p. 406-415.

[14] L. A. Mateos, M. Sousa, M. Vincze, DeWaLoP-Remote control for in-pipe robot. In: 2011 15th International Conference on Advanced Robotics (ICAR). IEEE, 2011. p. 518-523.

[15] T. Okada, T. Sanemori, MOGRER: A vehicle study and realization for in-pipe inspection tasks. IEEE Journal on Robotics and Automation, 1987, 3.6: 573-582.

[16] T. Oya, T. Okada, Development of a steerable, wheel-type, in-pipe robot and its path planning. Advanced Robotics, 2005, 19.6: 635-650.

[17] J. Min, W. Jeong, P. S. Pratama, and Y. D. Setiawan, "Fault diagnosis system of caterpillar wheel type pipeline inspection robot," Int. Symp. Mechatronics Robot., no. December 2013, pp. 1-5, 2013.

[18] M. M. Moghaddam, A. Hadi, Control and guidance of a pipe inspection crawler (PIC). In International symposium on automation and robotics. 2005. p. 11-14.

[19] L. A. Mateos, M. Sousa, M. Vincze, DeWaLoP-Remote control for in-pipe robot. In: 2011 15th International Conference on Advanced Robotics (ICAR). IEEE, 2011. p. 518-523.

[20] X. Zhan, H. Xu. J. Fang, and K. W. Wang, Planar locomotion of earthworm-like metameric robots. The International Journal of Robotics Research, 2019, 38.14: 17511774.

[21] W. Neubauer, A spider-like robot that climbs vertically in ducts or pipes. In: Proceedings of IEEE/RSJ International Conference on Intelligent Robots and Systems (IROS'94). IEEE, 1994. p. 1178-1185.

[22] A. Zagler, F. Pfeiffer, " Moritz" a pipe crawler for tube junctions. In: 2003 IEEE international conference on robotics and automation (Cat. No. 03CH37422). IEEE, 2003. p. $2954-$ 2959.

[23] M. Horodinca, I. Doroftei, E. Mignon, and A. Preumont, A simple architecture for in-pipe inspection robots. In: Proc. Int. Colloq. Mobile, Autonomous Systems. 2002. p. 61-64.

[24] T. Ren, Y. Li. Y. Zhang, Y. Chen, \& Q.Liu, Driving Mechanisms, Motion, and Mechanics of Screw Drive In-Pipe Robots: A Review. Applied Sciences, 2019, 9.12: 2514.

[25] HU. Zheng, E. Appleton, Dynamic characteristics of a novel self-drive pipeline pig. IEEE Transactions on Robotics, 2005, 21.5: 781-789.

[26] S. G. NO, S. M. Ryu, H. R. Choe, Development of Differentially Driven Inpipe Inspection Robot for Underground Gas Pipeline. Transactions of the Korean Society of Mechanical Engineers A, 2001, 25.12: 2019-2029.

[27] M. Horodinca, I. Doroftei, E. Mignon, and A. Preumont, A simple architecture for in-pipe inspection robots. In: Proc. Int. Colloq. Mobile, Autonomous Systems. 2002. p. 61-64.

[28] N. Miyagawa, I. Toyomi, "Step Climbing of In-pipe Mobile Robot with Wheel Drive Mechanism using Planetary Gear Drive," J. Japan Soc. Precis. Eng., vol. 73, pp. 828-833, 2007, DOI: 10.2493/jjspe.73.828.

[29] LI. Yang; LI. Man-tian, L. n. Sun, Design and passable ability of transitions analysis of a six legged wall-climbing robot. In: 2007 International Conference on Mechatronics and Automation. IEEE, 2007. p. 800-804.

[30] O. Tatar, D. Mandru, I. Ardelean, Development of mobile minirobots for in pipe inspection tasks. Mechanika, 2007, 68.6. [31] J. K. Ong, D. Kerr, K. Bouazza-Marouf, Design of a semiautonomous modular robotic vehicle for gas pipeline inspection. Proceedings of the Institution of Mechanical Engineers, Part I: Journal of Systems and Control Engineering, 2003, 217.2: 109-122.

[32] H. B. Kuntze, H. Haffner, Experiences with the development of a robot for smart multisensoric pipe inspection. In: Proceedings. 1998 IEEE International Conference on 
Robotics and Automation (Cat. No. 98CH36146). IEEE, 1998. p. 1773-1778.

[33] K. U. Scholl, V. Kepplin, K. Berns, and R. Dillmann, Controlling a multi-joint robot for autonomous sewer inspection. In: Proceedings 2000 ICRA. Millennium Conference. IEEE International Conference on Robotics and Automation. Symposia Proceedings (Cat. No. 00CH37065). IEEE, 2000. p. 1701-1706.

[34] Y. Kawaguchi, I. Yoshida, H. Kurumatani, T. Kikuta, and Y.A.Y.Y. Yamada, Internal pipe inspection robot. In: Proceedings of 1995 IEEE International Conference on Robotics and Automation. IEEE, 1995. p. 857-862.

[35] S. Fujiwara, R. Kanehara, T. Okada, and T. Sanemori, An articulated multi-vehicle robot for inspection and testing of pipeline interiors. In: Proceedings of 1993 IEEE/RSJ International Conference on Intelligent Robots and Systems (IROS'93). IEEE, 1993. p. 509-516.

[36] Li. P. Ma, S. Li. B, and Y. Wang, Design of a mobile mechanism possessing driving ability and detecting function for in-pipe inspection. In: 2008 IEEE International Conference on Robotics and Automation. IEEE, 2008. p. 3992-3997.

[37] S. G. Roh, J. S. Lee, H. Moon, and H. R. Choi, In-pipe robot based on selective drive mechanism. International Journal of Control, Automation, and Systems, 2009, 7.1: 105-112.

[38] Z. Wang, GU. Hong, A bristle-based pipeline robot for illconstraint pipes. IEEE/ASME Transactions on Mechatronics, 2008, 13.3: 383-392.

[39] Z. HU, E. Appleton, Dynamic characteristics of a novel self-drive pipeline pig. IEEE Transactions on Robotics, 2005, 21.5: 781-789.

[40] Y. J. Kim, K. H. Yoon, Y. W. Park, Development of the inpipe robot for various sizes. In: 2009 IEEE/ASME International Conference on Advanced Intelligent Mechatronics. IEEE, 2009. p. 1745-1749.

[41] R. Aracil, R. Saltaren, O. Reinoso, Parallel robots for autonomous climbing along tubular structures. Robotics and Autonomous Systems, 2003, 42.2: 125-134.

[42] W. Jeon, J. Park, I. Kim, Y. K. Kang, and H. Yang, Development of high mobility in-pipe inspection robot. In: 2011 IEEE/SICE International Symposium on System Integration (SII). IEEE, 2011. p. 479-484.

[43] W. Neubauer, A spider-like robot that climbs vertically in ducts or pipes. In: Proceedings of IEEE/RSJ International Conference on Intelligent Robots and Systems (IROS'94). IEEE, 1994. p. 1178-1185.

[44] A. Zagler, F. Peeiffer, " Moritz" a pipe crawler for tube junctions. In: 2003 IEEE international conference on robotics and automation (Cat. No. 03CH37422). IEEE, 2003. p. 29542959.

[45] A. Kuwada, S. Wakimoto, K. Suzumori, and Y. Adomi, Automatic pipe negotiation control for snake-like robot. In: 2008 IEEE/ASME International Conference on Advanced Intelligent Mechatronics. IEEE, 2008. p. 558-563.

[46] S. A. Fjerdingen, P.Liueback, A. A. Transeth, "Asnake-like robot for internal inspection of complex pipe structures (PIKo). In: 2009 IEEE/RSJ International Conference on Intelligent Robots and Systems. IEEE, 2009. p. 5665-5671.

[47] C. Wright, A. Johnson, A. Peck, Z. McCord, A. Naaktgeboren, P. Gianfortoni, \& H. Choset, Design of a modular snake robot. In: 2007 IEEE/RSJ International Conference on Intelligent Robots and Systems. IEEE, 2007. p. 2609-2614.

[48] S. Wakimoto, J. Nakajima, M. Takata, T. Kanda, and K.Suzumori, A micro snake-like robot for small pipe inspection. In: MHS2003. Proceedings of 2003 International Symposium on Micromechatronics and Human Science (IEEE Cat. No. 03TH8717). IEEE, 2003. p. 303-308.

[49] N. S. Roslin, A. Anuar, M. F. A. Jalal, and K. S. M, Sahari, A review: Hybrid locomotion of in-pipe inspection robot. Procedia Engineering, 2012, 41: 1456-1462.

[50] L. A. L. A. Mateos, M. Vincze, In-pipe robot with capability of self-stabilization and accurate pipe surface cleaning. In: Proceedings of the IEEE International Conference on Automation Science and Engineering. 2013.p. 7.

[51] H. Schempf, E. Mutschler, V. Goltsbergm, and W. Crowley, Grislee: Gasmain repair and inspection system for live entry environments. The International Journal of Robotics Research, 2003, 22.7-8: 603-616.

[52] N. Truong-Thinh, N. Ngoc-Phuong, T. Phuoc-Tho, A study of pipe-cleaning and inspection robot. In: 2011 IEEE International Conference on Robotics and Biomimetics. IEEE, 2011. p. 2593-2598.

[53] M. A. Muthugala, M. Vega-Heredia, R. E. Mohan, and S. R. Vishaal, Design and Control of a Wall Cleaning Robot with Adhesion-Awareness. Symmetry, 2020, 12.1: 122.

[54] J. Saenz, N. Elkmann, T. Stuerze, S. Kutzner, and H, Althoff, Robotic systems for cleaning and inspection of large concrete pipes. In: 2010 1st International Conference on Applied Robotics for the Power Industry. IEEE, 2010. p. 1-7.

[55] R. Sam, K. Ariffin, N. Buniyamin, Simulation of pick and place robotics system using Solidworks Softmotion. In: 2012 International Conference on System Engineering and Technology (ICSET). IEEE, 2012. p. 1-6.

[56] "AISI 1035 Carbon Steel (UNS G10350)." https://www.azom.com/article.aspx?ArticleID=6540 (accessed Feb. 15, 2019).

[57] "Wrought aluminum alloy 1060 [SubsTech]." https://www.substech.com/dokuwiki/doku.php?id=wrought_al uminum_alloy_1060 (accessed Feb. 15, 2019).

[58] Ronald C. Arkin, Behaviors based robotics, Publisher: MIT Press, 55 Hayward St., Cambridge, MA, United States, ISBN: 978-0-262-01165-5, 1998

[59] https://simplemotor.com/calculations

"Calculations|Simple Electric Motors." / (accessed 1th June 2020) 